NASA TECHNICAL NOTE

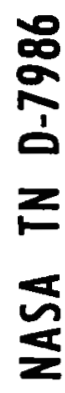<smiles>[AlH2]</smiles>

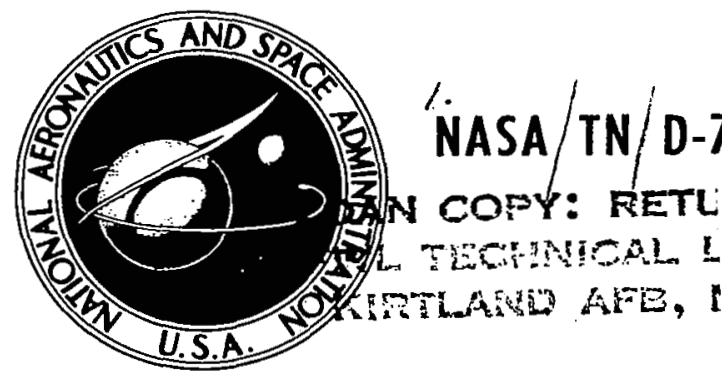

7986

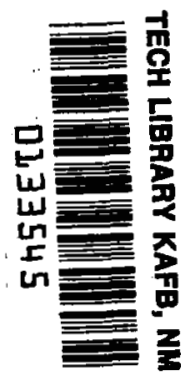

4.

FRICTION AND WEAR

OF METALS IN CONTACT

WITH PYROLYTIC GRAPHITE,

Donald H. Buckley and William A. Brainard

Lewis Research Center

Cleveland, Ohio 44135

3

NATIONAL AERONAUTICS AND SPACE ADMINHSTRATHOH- - WASHINGTON, D. C. - JUNE WRT5 


\begin{tabular}{|c|c|c|c|c|}
\hline $\begin{array}{l}\text { 1. Report No. } \\
\text { NASA TN D-7986 }\end{array}$ & \multicolumn{2}{|c|}{ 2. Government Accession No. } & \multicolumn{2}{|c|}{ 3. Recipient's Catalog No. } \\
\hline \multirow{2}{*}{\multicolumn{3}{|c|}{$\begin{array}{l}\text { 4. Title and Subtitle } \\
\text { FRICTION AND WEAR OF METALS IN CONTACT WITH } \\
\text { PYROLYTIC GRAPHITE }\end{array}$}} & \multicolumn{2}{|c|}{$\begin{array}{l}\text { 5. Report Date } \\
\text { June } 1975 \\
\end{array}$} \\
\hline & & & \multicolumn{2}{|c|}{ 6. Performing Organization Code } \\
\hline \multicolumn{3}{|c|}{$\begin{array}{l}\text { 7. Author(s) } \\
\text { Donald H. Buckley and William A. Brainard }\end{array}$} & \multicolumn{2}{|c|}{$\begin{array}{l}\text { 8. Performing Organization Report No. } \\
\text { E-8195 }\end{array}$} \\
\hline \multirow{3}{*}{\multicolumn{3}{|c|}{$\begin{array}{l}\text { 9. Performing Organization Name and Address } \\
\text { Lewis Research Center } \\
\text { National Aeronautics and Space Administration } \\
\text { Cleveland, Ohio } 44135\end{array}$}} & \multicolumn{2}{|l|}{$\begin{array}{l}\text { 10. Work Unit No. } \\
506-16\end{array}$} \\
\hline & & & \multicolumn{2}{|c|}{ 11. Contract or Grant No. } \\
\hline & & & \multirow{2}{*}{\multicolumn{2}{|c|}{$\begin{array}{l}\text { 13. Type of Report and Period Covered } \\
\text { Technical Note }\end{array}$}} \\
\hline \multirow{2}{*}{\multicolumn{3}{|c|}{$\begin{array}{l}\text { 12. Sponsoring Agency Name and Address } \\
\text { National Aeronautics and Space Administration } \\
\text { Washington, D.C. } 20546\end{array}$}} & & \\
\hline & & & \multicolumn{2}{|c|}{ 14. Sponsoring Agency Code } \\
\hline \multicolumn{5}{|l|}{ 15. Supplementary Notes } \\
\hline \multicolumn{5}{|c|}{$\begin{array}{l}\text { 16. Abstract } \\
\text { Sliding friction experiments were conducted with gold, iron, and tantalum single crystals sliding } \\
\text { on prismatic and basal orientations of pyrolytic graphite in various environments, including } \\
\text { vacuum, oxygen, water vapor, nitrogen, and hydrogen bromide. Surfaces were examined in the } \\
\text { clean state and with various adsorbates present on the graphite surfaces. LEED, Auger spec- } \\
\text { troscopy, SEM, and EDXA were used to characterize the graphite surfaces. Results indicate } \\
\text { that the prismatic and basal orientations do not contain nor do they chemisorb oxygen, water } \\
\text { vapor, acetylene, or hydrogen bromide. All three metals exhibited higher friction on the pris- } \\
\text { matic than on the basal orientation and these metals transferred to the atomically clean prismatic } \\
\text { orientation of pyrolytic graphite. No metal transfer to the graphite was observed in the presence } \\
\text { of adsorbates at } 760 \text { torr. Ion bombardment of the graphite surface with nitrogen ions resulted } \\
\text { in the adherence of nitrogen to the surface. }\end{array}$} \\
\hline \multicolumn{2}{|c|}{$\begin{array}{l}\text { 17. Key Words (Suggested by Author(s)) } \\
\text { Friction; Wear; Pyroly tic graphite; } \\
\text { Adsorption; LEED and Auger spectroscopy }\end{array}$} & \multicolumn{3}{|c|}{$\begin{array}{l}\text { 18. Distribution Statement } \\
\text { Unclassified - unlimited } \\
\text { STAR Category } 27 \text { (rev.) }\end{array}$} \\
\hline $\begin{array}{l}\text { 19. Security Classif. (of this rep } \\
\text { Unclassified }\end{array}$ & $\begin{array}{r}\text { 20. Security Cla } \\
\text { Uno }\end{array}$ & $\begin{array}{l}\text { f this page) } \\
\text { sified }\end{array}$ & \begin{tabular}{|l} 
21. No. of Pages \\
25
\end{tabular} & $\begin{array}{l}\text { 22. } \text { Price* }^{*} \\
\$ 3.75\end{array}$ \\
\hline
\end{tabular}

* For sale by the National Technical Information Service, Springfield, Virginia 22151 


\title{
FRICTION AND WEAR OF METALS IN CONTACT WITH PYROLYTIC GRAPHITE
}

\author{
by Donald H. Buckley and William A. Brainard \\ Lewis Research Center
}

\author{
SUMMARY
}

Sliding friction experiments were conducted with gold, iron, and tantalum single crystals sliding on prismatic and basal orientations of pyrolytic graphite in various environments, including vacuum, oxygen, water vapor, nitrogen, and hydrogen bromide. Surfaces were examined in the clean state and with various adsorbates present on the graphite surfaces. LEED, Auger spectroscopy, SEM, and EDXA were used to characterize the graphite surfaces. Results indicate that the prismatic and basal orientations do not contain nor do they chemisorb oxygen, water vapor, acetylene, or hydrogen bromide. All three metals exhibited higher friction on the prismatic than on the basal orientation and these metals transferred to the atomically clean prismatic orientation of pyrolytic graphite. No metal transfer to the graphite was observed in the presence of adsorbates at 760 torr. Ion bombardment of the graphite surface with nitrogen ions resulted in the adherence of nitrogen to the surface.

\section{INTRODUCTION}

Graphite and carbon-graphite bodies are widely used in the field of lubrication. Graphite is used as a solid lubricant (refs. 1 to 3). Carbon-graphite bodies are used as components in such devices as mechanical seals (ref. 4) and electrical brushes (refs. 5 and 6). Thus, the fundamental adhesion, friction, and wear behavior of these materials is of interest.

Pyrolytic graphite prepared by the high temperature decomposition of hydrocarbons affords a source of high purity carbon in graphitic form. Orientation effects can readily be studied with this material. Further, it has many properties which make it an ideal material for use in lubrication systems.

Generally the solid state contact of carbon-graphite bodies is not against itself in lubricating devices but rather against metals. The interactions of metals with graphitic 
carbon of differing orientations and the effect of surface films on those interactions therefore are important.

The objectives of this investigation were to deter mine the effect of (1) orientation, (2) reactivity of the metal, and (3) the effect of surface films on the friction and wear of metals in contact with pyrolytic graphite. Low energy electron diffraction (LEED), Auger emission spectroscopy analysis, scanning electron microscopy (SEM), and energy dispersive $\mathrm{X}$-ray analysis (EDXA) were used to characterize and monitor surface changes. The metals gold, iron, and tantalum were selected for study because of their different reactivity toward carbon. Gold does not react chemically while tantalum does so very strongly. Iron lies between gold and tantalum in its reactivity toward carbon.

\section{MATERIALS}

The pyrolytic graphite was prepared from the thermal decomposition of hydrocarbons. It was machined into cylinders 8.0 millimeters in diameter by 5.0 millimeters in length with the basal orientation parallel to the cylinder axis (prismatic orientation) or perpendicular to the axis (basal orientation) as desired. A fresh surface was prepared by polishing with 600 grit abrasive paper. A basal surface was also prepared by cleavage with a razor blade.

The metal pin specimens contacting the pyrolytic graphite were gold, iron, and tantalum single crystals. The pins were cylindrical with a 2 millimeter diameter and a 2.0 millimeter radius on one end (the contacting surface). The gold and iron were 99. 99 percent pure, and the tantalum was 99.98 percent pure. With gold the (111) plane was parallel to the contacting interface to within $\pm 2^{\circ}$. For both iron and tantalum the (110) plane was parallel $( \pm 29$ to the contacting interface. The metal crystal contacting radius was electropolished prior to use.

\section{APPARATUS}

The apparatus used in this investigation was a vacuum system with the capability of measuring adhesion, load, and friction and also performing Auger and LEED surface analysis. A diagram of the apparatus for the measurement of adhesion, loading, and friction is shown schematically in figure 1.

A gimbal mounted beam projects into the vacuum system. The beam contains two flats machined normal to each other with strain gages mounted thereon. The gold, iron, and tantalum single crystal pin specimens are mounted on the end of the beam. A load is applied by moving the beam toward the disk. Load is measured by the strain gage. 
Adhesive forces are measured by moving the beam in the direction opposite to which the load was applied (see fig. 1).

Tangential motion of the pin along the disk surface is accomplished through the gimbal assembly. Friction force is measured by the strain gage normal to that used to measure load. In the present study full-scale deflection on a conventional strip chart recorder resulted from a 10-gram load.

Multiple wear tracks could be generated on the disk surface by translating the beam containing the pin. Pin sliding was in the vertical direction in figure 1.

In addition to the friction apparatus the experimental chamber also had a LEED diffraction system and an Auger spectrometer. The electron beam of both could be focused on any disk site.

The vacuum system was a conventional vacsorb and ion pumped system capable of readily achieving pressures of $10^{-10}$ torr as measured by a nude ionization gage. Sublimation pumping was also used.

\section{EXPERIMENTAL PROCEDURE}

The pyrolytic graphite carbon disk and the metal pin were rinsed with 200 proof ethyl alcohol just prior to insertion into the vacuum system. The system was evacuated with sorption and ion pumps and baked out overnight at $250^{\circ} \mathrm{C}$.

After the specimens were cooled to room temperature, the surfaces were examined with both LEED and Auger analysis. When the surfaces were fully characterized by these techniques, friction experiments were initiated.

The pin was brought into contact with the disk, and loads of from 1 to 10 grams were applied to the pin in 1-gram increments. The load applied was continuously monitored on a strip chart recorder. Sliding was then initiated by driving the pin across the disk surace in the vertical direction of figure 1. Friction force was also continuously monitored during slidiing. After sliding 5 millimeters, the drive was stopped, load removed, and adhesion force measured.

The disk surface of pyrolytic graphite was again reexamined with LEED and Auger analysis after sliding was complete. The specimens were subsequently removed from the vacuum chamber and examined in the SEM with EDXA to determine if metal transferred to the pyrolytic graphite.

Gases were bled into the system through a leak valve. Pressure was monitored with the nude ionization gage and a ther mocouple gage.

In some experiments the specimens of pyrolytic graphite were nitrogen ion sputter bombarded using nitrogen ion bombardment. A nitrogen pressure of $10^{-3}$ torr and an ionization voltage of 1000 volts for a period of 30 minutes were used. 


\section{RESULTS}

\section{Surface Characterization}

It has been the generally accepted belief for some time that the surface of graphite contains adsorbed oxygen which can only be removed as $\mathrm{CO}$ and $\mathrm{CO}_{2}$ by heating to $1000^{\circ} \mathrm{C}$ in vacuum (see refs. 7 and 8 for summaries). Most of these studies concluded that oxygen was present on the graphite surface from indirect measurements such as mass spectrometry.

Auger spectroscopic analyses of both the basal and prismatic orientations of pyrolytic graphite were conducted. The results obtained are presented in figures 2 and 3 . With both spectra the only Auger peak detected was that of carbon. The carbon Auger peak occurs at 272 electron volts and the oxygen at 511 electron volts. If oxygen were present on either surface, a peak would occur to the right of the carbon peak in figures 2 and 3 .

It should be indicated that Auger spectroscopy analysis is sensitive to oxygen surface coverages as low as 0.01 monolayer (ref. 9). Thus, if oxygen is present on either the prismatic or basal orientation of pyrolytic graphite, it is less than 0.1 monolayer. These results are consistent with the observations of Hart, Vastola, and Walker (ref. 10).

A LEED pattern was obtained from the basal orientation of pyrolytic graphite. The pattern is presented in figure 4. A ring structure is present. The pattern is not that seen for single crystal graphite (ref. 11). This may be due to rotational symmetry effects (refs. 12 and 13).

The LEED pattern of figure 4 reflects a strained surface lattice. An analogous pattern was found for the basal orientation of pyrolytic graphite with conventional electron diffraction in reference 14 . Annealing at $3600^{\circ} \mathrm{C}$ in reference 14 removed the strain and gave a sharp spot diffraction pattern. The system of the present study was not capable of achieving such temperatures. Presumably annealing would result in a sharp diffraction pattern.

Attempts were made to adsorb various surface active species on the pyrolytic graphite surface. The halogens in general and bromine in particular appear to interact with graphite (refs. 15 and 16). The basal orientation of pyrolytic graphite was exposed to $10^{-2}$ torr-second (10 000 Langmuirs) of hydrogen bromide. Hydrogen bromide failed to adsorb to graphite as indicated by the absence of any peak other than carbon in figure 5 .

In an attempt to achieve bonding of species to the pyrolytic graphite, the pyrolytic graphite was bombarded with ions of the gases sought to be adsorbed. Nitrogen, for example, did not adsorb to the graphite and remain on the surface at $10^{-10}$ torr. If, 
however, the specimen was bombarded with nitrogen ions generated at a pressure of $10^{-2}$ torr and the system reevacuated to $10^{-10}$ torr, nitrogen remained on the surface as indicated in the data of figure 6 . In figure 6 both carbon and nitrogen peaks are present.

Graphite depends on the presence of adsorbates for its lubricating characteristics (ref. 17). Savage (ref. 17) found that graphite will not lubricate in a hard vacuum because of desorption of such adsorbed species as water and hydrocarbons. Ion bombardment may be a technique for attaching or embedding species in the graphite surface.

\section{Gold}

Gold was selected as a pin material because it is nonreactive with carbon and can be relatively easily cleaned. The gold pin was heated to $700^{\circ} \mathrm{C}$ for 1 hour and then cooled to room temperature. It was slid on the two orientations of pyrolytic graphite in separate experiments. Experiments were conducted both at $23^{\circ} \mathrm{C}$ at various loads and at temperatures to $700^{\circ} \mathrm{C}$. Friction results obtained are presented in figure 7 .

In figure 7 (a) friction is unaffected by load but is higher for the prismatic orientation at all loads. The friction coefficient on the basal orientation exceeds 0.4 and for the prismatic orientation it is 0.6. SEM photographs of the two surfaces after sliding are presented in figure 8 .

Figure 8(a) indicates the basal orientation of pyrolytic graphite after sliding. There was an absence of any gold. On the prismatic orientation, however, small spheres of transferred gold were observed (see fig. 8(b)). Note the exposed edges of the graphite prismatic orientation in figure $8(\mathrm{~b})$.

The prismatic orientation of graphite is from 500 to $10^{3}$ times more chemically active than is the basal orientation (ref. 18). It has been indicated that the surface energy of the basal orientation of graphite is only a few hundred ergs per square centimeter, while for the prismatic orientation, it is 5000 ergs per square centimeter (ref. 19). When the basal orientation of graphite is decorated with gold to study vacancy loops, the gold is found to migrate on the surface to steps (ref. 14). The steps are higher energy sites (exposure of prismatic planes) and therefore the migration indicates stronger binding interaction of the gold with the prismatic planes than with basal planes.

The difference in friction coefficients with the two orientations of pyrolytic graphite in figure $7(a)$ and the transfer of gold to the prismatic orientation must be related to binding energies because, as will be shown later, metal transfer to this orientation will not occur in the presence of physically adsorbed films.

The friction behavior of gold in contact with the two orientations of pyrolytic graphite at various temperatures is presented in figure $7(\mathrm{~b})$. The friction coefficient for the basal orientation continuously decreases with increases in temperature, while the friction for the prismatic orientation increases with increases in temperature. The friction 
coefficient for the basal orientation at $700^{\circ} \mathrm{C}$ is less than half the value at $23^{\circ} \mathrm{C}$, while for the prismatic orientation the friction has increased twofold over the same temperature range.

\section{Iron}

Sliding friction experiments were conducted with the (110) orientation of a single crystal iron pin sliding across the basal and prismatic orientations of pyrolytic graphite at room temperature and $700^{\circ} \mathrm{C}$. The results obtained are presented in figure 9.

In figure 9 at both temperatures the prismatic orientations gave higher friction coefficients than the basal orientations. For both orientations the friction coefficient was lower at $700^{\circ} \mathrm{C}$ than it was at $23^{\circ} \mathrm{C}$. With the prismatic orientation at both temperatures an increase in friction coefficient occurred at loads in excess of 6 grams.

The friction behavior of the iron sliding on the prismatic orientation was characterized by a marked stick-slip pattern. This is shown in the data of figure 10. At both $23^{\mathrm{O}}$ and $700^{\circ} \mathrm{C}$ a regular stick-slip pattern, continuous in nature, occurs with sliding indicating a repetitious breaking of adhesive junctions at the interface. Thus, bonding of the iron to the prismatic planes of the pyrolytic graphite must be occurring. With an increase in the temperature from $23^{\circ}$ to $700^{\circ} \mathrm{C}$ there is simply a reduction in bond strength.

While the prismatic edges of the graphite crystallites appear as knife edges and are harder than the diamond form of carbon (see fig. 8(b)) a shearing or cutting action by the edges is doubted. The reasons for this are twofold: (1) the traces in figure 10 are regular and "stick-slip" in nature, as discussed later, and (2) in the presence of adsorbates, metallic debris is not found on the graphite surface.

Wear tracks generated on the basal orientation of pyrolytic graphite with sliding at $23^{\circ}$ and $700^{\circ} \mathrm{C}$ are presented in figure 11. Examination of the two micrographs indicates that the basal planes are torn into ribbons during the sliding process. This tearing action can be initiated by adhesion of the iron to the basal plane with subsequent fracture in the basal plane with tangential sliding on the contact of the iron pin with cleavage steps on the surface. If the latter accounts for the tearing, then temperature should have little effect; yet a comparison of figures $11(a)$ and (b) indicates that it does.

There was no evidence found either with Auger analysis on EDXA for the transfer of iron to the basal orientation of pyrolytic graphite. In this respect gold and iron behaved in a similar manner. Neither transferred to the basal orientation despite differences in chemical activity. Ir on can covalently bond to the carbon (ref. 20).

With the prismatic orientation iron was found to transfer to the pyrolytic graphite. One such piece of transferred iron is seen in the SEM of figure 12(a) and its identity 
established as iron in the EDXA map of figure 12(b). The sizes of the transferred particles were generally larger than seen with gold.

If a current was allowed to flow through the iron-carbon interface for the basal orientation of pyrolytic graphite while sliding, globules of iron were found on the graphite surface. The globules were largely spherical in nature as indicated by the SEM micrograph of figure 13(a) and the EDXA map of figure 13(b). Thus, it appears that iron does not wet the basal orientation of pyrolytic graphite. This may explain why iron has been observed to "sweat" out of graphite composite bodies (ref. 21).

\section{Tantalum}

Coefficient of friction was measured for a (110) oriented single crystal pin of tantalum sliding on the basal and prismatic orientations of pyrolytic graphite. The results obtained are presented in figure 14 for measurements at $23^{\circ}$ and $700^{\circ} \mathrm{C}$. As with gold and iron the prismatic orientation of pyrolytic graphite gave the highest friction coefficient at both temperatures. At $23^{\circ} \mathrm{C}$ the friction coefficient was 1.0 for loads in excess of 5 grams.

The friction coefficient for the basal orientation remained unchanged with an increase in temperature from $23^{\circ}$ to $700^{\circ} \mathrm{C}$. With iron there was a decrease in friction in increasing the temperature from $23^{\circ}$ to $700^{\circ} \mathrm{C}$. Tantalum is chemically more reactive with carbon than is iron (ref. 22). This may account for the difference in behavior because higher temperatures are needed to break the bonds.

If the tantalum bonds more strongly to the pyrolytic graphite than either iron or gold, then the friction results presented can be explained on the basis of this behavior. The greater the chemical interaction of the metal with carbon atoms in the basal sheets, the greater is the stress and the lower is the force required to fracture the planes. With the prismatic orientation the interaction is stronger; therefore, the adhesive bonding is stronger.

If is of interest to note that the wear particle size requiring shearing increased with an increase in the chemical activity of the metal to carbon for the prismatic orientation of the pyrolytic graphite. Figure 15 indicates tantalum transferred to the prismatic orientation. A particle is shown in figure 15(a) and the EDXA map thereof is figure 15(b).

An examination of the EDXA map of figure 15(b) indicates that the map only reveals the tantalum for the upper portion of the particle seen in figure 15(a). It is believed that the lower portion of the particle may have reacted with the graphite to form tantalum carbide. 
Savage (ref. 17) and Campbell and Kozak (ref. 6) have shown the importance of adsorbed films on the wear behavior of graphite and carbons. In the present study the effects of a hydrocarbon, water, and oxygen on friction coefficient were determined for iron in contact with pyrolytic graphite. The prismatic orientation of atomically clean pyrolytic graphite was exposed to 760 torr of acetylene, water vapor, and oxygen. The friction results obtained sliding in each of these environments are presented in figure 16.

Examination of figure 16 indicates that, at loads of 6 grams and less, acetylene did not affect the friction results obtained in figure 9 for adsorbate free graphite. Above 6 grams, the hydrocarbon, acetylene, did exert an effect in the reduction of friction. Both oxygen and water vapor did reduce friction coefficients from the values obtained in figure 9 at all temperatures. Oxygen and water vapor yielded data which could be plotted on a single curve.

The atmospheres of oxygen and water vapor did allow the graphite crystallites to reorient themselves on the surface from the prismatic to the basal orientation with sliding as indicated in figure 17. This effect was observed with both oxygen and water vapor but was not seen in the absence of these vapors (see fig. 8(b)). LEED examination of the contact area after sliding indicated that a ring structure similar to that seen in figure 4 was observed. The prismatic orientation did not yield any LEED pattern.

At the lower loads of figure 16 many of the data points are at about the same friction values seen in figure 9 for the clean basal orientation of graphite indicating that at these loads the adsorbates have little effect upon friction. At the higher loads, there is, however, a very definite influence due to the adsorbate itself aside from changes in orientation.

The work of Savage (ref. 17) indicated that the wear rate of graphite was sensitive to changes in water vapor pressure. Sliding was therefore conducted at a pressure of 1 torr and the results are compared with those obtained at 760 torr in figure 18. The data of figure 18 indicate that water vapor pressure has a definite effect upon the friction behavior of the prismatic orientation of pyrolytic graphite.

Auger analysis was made of the pyrolytic graphite surfaces after exposure to acetylene, oxygen, and water vapor. The experimental chamber was evacuated, and Auger spectra were obtained. No evidence for any of the adsorbates was found. These results together with those of reference 10 indicate that the long held concept of oxygen being heavily adsorbed at graphite crystallite edges is not correct. If oxygen is present, it is there in less than 0.01 monolayer. 


\section{DISCUSSION}

The direct analysis of the prismatic planes of pyrolytic graphite in this study indicates that the maximum surface coverage on these planes with adsorbates must be less than 0.01 monolayer, the limit for Auger spectroscopy analysis. Thus, many of the early studies using change of weight measurements and mass spectrometry analysis of gases to detect adsorbed films on graphite may have been misleading ( $r$ efs. 7 and 8 ).

In the present study even hydrogen bromide would not adsorb on pyrolytic graphite and remain. Only when the graphite surface was ion bombarded with an adsorbing species (nitrogen) did it remain on or embedded in the surface. This process went bey ond simple adsorption, and chemical interaction to form a carbon-nitrogen covalent chemi cal bond was certain to have occurred.

The ion bombardment to achieve attachment of foreign atoms to the basal surface of graphite has some interesting implications to lubrication. It appears that those elements which can chemically interact with graphite can be attached to its surface by ion bombardment and thereby reduce friction and wear of graphite at reduced pressures and in the absence of adjuvants.

Apparently at atmospheric pressure water vapor, oxygen, and to a lesser extent, acetylene do affect friction behavior. A part of that effect may be due simply to the presence of the gas facilitating reorientation of the graphite crystallites as indicated by the data. Some of the effect is, however, due simply to the presence of the physically adsorbed gas because, as the data indicated, friction was less than observed for the clean basal orientation of pyrolytic graphite when the gases were present at atmospheric pressure.

Metal transferred to the clean prismatic orientation of pyrolytic graphite with gold, iron, and tantalum. The experimental results indicate that strong bonding of the metal to the carbon atoms must occur. The stick-slip nature of the friction trace of figure 10 indicates this strong adhesion. The metal transfer is not due to a simple mechanical action of the crystallite edges on the metal. If this were the case, then metal transfer should also have been seen in the presence of the adsorbates but it was not.

The presence of the adsorbates must cover not only prismatic sites but also the basal planes allowing them to move freely with sliding activity and thus reorient on the surface. This freedom of mobility must be considered in the potential activity by the prismatic planes. The freedom would certainly tend to reduce the activity.

Both iron and tantalum interact with carbon to form strong chemical bonds. Thus, strong adhesion of these metals to the most chemically active planes of graphite is not surprising. Gold, however, is not known to strongly interact with carbon; and its sister noble metals, copper and silver, do not even wet graphite (ref. 21). Notwithstanding these facts, however, relatively high friction forces were measured for clean gold in 
contact with clean pyrolytic graphite. A strong bonding interaction must therefore occur.

\section{SUMMARY OF RESULTS}

The following results were obtained from an investigation with gold, iron, and tantalum in sliding contact with the basal and prismatic orientations of pyrolytic graphite and from a surface analysis of the pyrolytic graphite:

1. Neither the edges (prismatic orientation) nor the basal orientation of pyrolytic graphite chemisorbed gases such as hydrogen bromide, oxygen, water vapor, and acetylene in surface coverages in excess of 0.01 monolayer.

2. With all three metals, gold, iron, and tantalum, lower friction coefficients were measured for the basal than for the prismatic orientation of pyrolytic graphite.

3. Metal transfer to the clean prismatic orientation of pyrolytic graphite was observed with all three metals.

4. The adsorbates oxygen, water vapor, and acetylene completely inhibited metal transfer to the prismatic orientation of pyrolytic graphite even though only physically adsorbed.

5. No metal transfer was observed to the basal orientation of pyrolytic graphite in normal sliding.

6. The presence of physically adsorbed gases on the prismatic orientation of pyrolytic graphite facilitated reorientation in the contact zone during sliding to the basal orientation.

7. Marked stick-slip behavior was observed for metals in contact with the clean prismatic orientation of pyrolytic graphite indicating strong adhesion between the carbon and metal.

8. Ion bombardment of the graphite surface with nitrogen resulted in strong bonding or embedding of the nitrogen to or in the carbon surface.

Lewis Research Center,

National Aeronautics and Space Administration, Cleveland, Ohio, March 25, 1975, 506-16.

\section{REFERENCES}

1. Bisson, E. E.; and Anderson, W. J.: Advanced Bearing Technology. NASA SP-38, 1964. 
2. Braithwaite, E. R.: Solid Lubricants and Surfaces. The MacMillan Co., 1964.

3. Clauss, F. J.: Solid Lubricants and Self-Lubricating Solids. Academic Press, 1972.

4. Lauzau, W. R.; Shelton, B. R.; and Waldheger, R. A.: The Use of CarbonGraphite in Mechanical Seals. Lubr. Eng., vol. 19, no. 5, May 1963, pp. 201209.

5. Holm, Ragnar: Electric Contacts. Uppsala, Almquist and Wiksells, 1946.

6. Campbell, W. E.; and Kozak, R.: Studies in Boundary Lubrication. III. The Wear of Carbon Brushes in Dry Atmospheres. ASME Trans., vol. 70, no. 5, July 1948, pp. $491-498$.

7. Bansal, R. C.; Vastola, F. J.; and Walker, P. L., Jr.: Studies in Ultra-Clean Carbon Surfaces. IV - Decomposition of Carbon-Oxygen Surface Complexes. Carbon, vol. 8, 1970, pp. 443-448.

8. Barton, S. S.; and Harrison, B. H.: Surface Studies on Graphite: Immersional Energetics. Carbon, vol. 10, 1972, pp. 245-251.

9. Musket, R. G.; and Ferrante, J.: Auger Electron Spectroscopy of Oxygen Adsorption on W (110). Jour. Vac. Sci. Tech., vol. 7, no. 1, 1970, pp. 14-17.

10. Hart, P. J.; Vastola, F. J.; and Walker, P. L., Jr.: Graphite-Oxygen Interactions. Carbon, vol. 5, 1967, p. 363.

11. Amelio, G. F.; and Scheibner, E. J.: Auger Spectroscopy of Graphite Single Crystals with Low Energy Electrons. Sur. Sci., vol. 11, 1968, pp. 242-254.

12. Buckley, D. H.: Adhesion of Metals to a Clean Ir on Surface Studied with LEED and Auger Emission Spectroscopy. Wear, vol. 20, 1972, pp. 89-103.

13. Leygraf, C.; and Ekelund, S.: A LEED-AES Study of the Oxidation of Fe (110) and Fe (100). Sur. Sci., vol. 40, 1973, pp. 609-635.

14. Thrower, P. A.: The Study of Defects in Graphite by Transmission Electron Microscopy. Chem. Phys. Carbon, vol. 5, 1969, pp. 217-319.

15. Hooley, J. G.: Kinetics of the Graphite-Bromine Reaction. Proceedings, Conference on Carbon, 3rd, 1957, pp. 347-348.

16. Hooley, Joseph G.: Intercalation Isotherms on Natural and Pyrolytic Graphite. Chem. Phys. Carbon, vol. 5, 1969, pp. 321-372.

17. Savage, Robert H.: Graphite Lubrication. Jour. App. Phys., vol. 19, no. 1, Jan. 1948, pp. 1-12. 
18. Henning, G. R.: Electron Microscopy of Reactivity Changes Near Lattice Defects in Graphite. Chem. Phys. Carbon, vol. 2, 1966, pp. 1-49.

19. Bowden, Frank P.; and Tabor, D.: The Friction and Lubrication of Solids. Oxford Press, 1964.

20. Azaroff, Leonid V.: Introduction to Solids. McGraw-Hill, 1960.

21. Humenik, N., Jr.: Ceramic-Metal Composites and Their Uses. The Science of Materials Used in Advanced Technology. Wiley-Interscience, 1973.

22. Sheipline, V. M.; and Runck, R. J.: Carbides, High Temperature Technology . Wiley, 1956. 


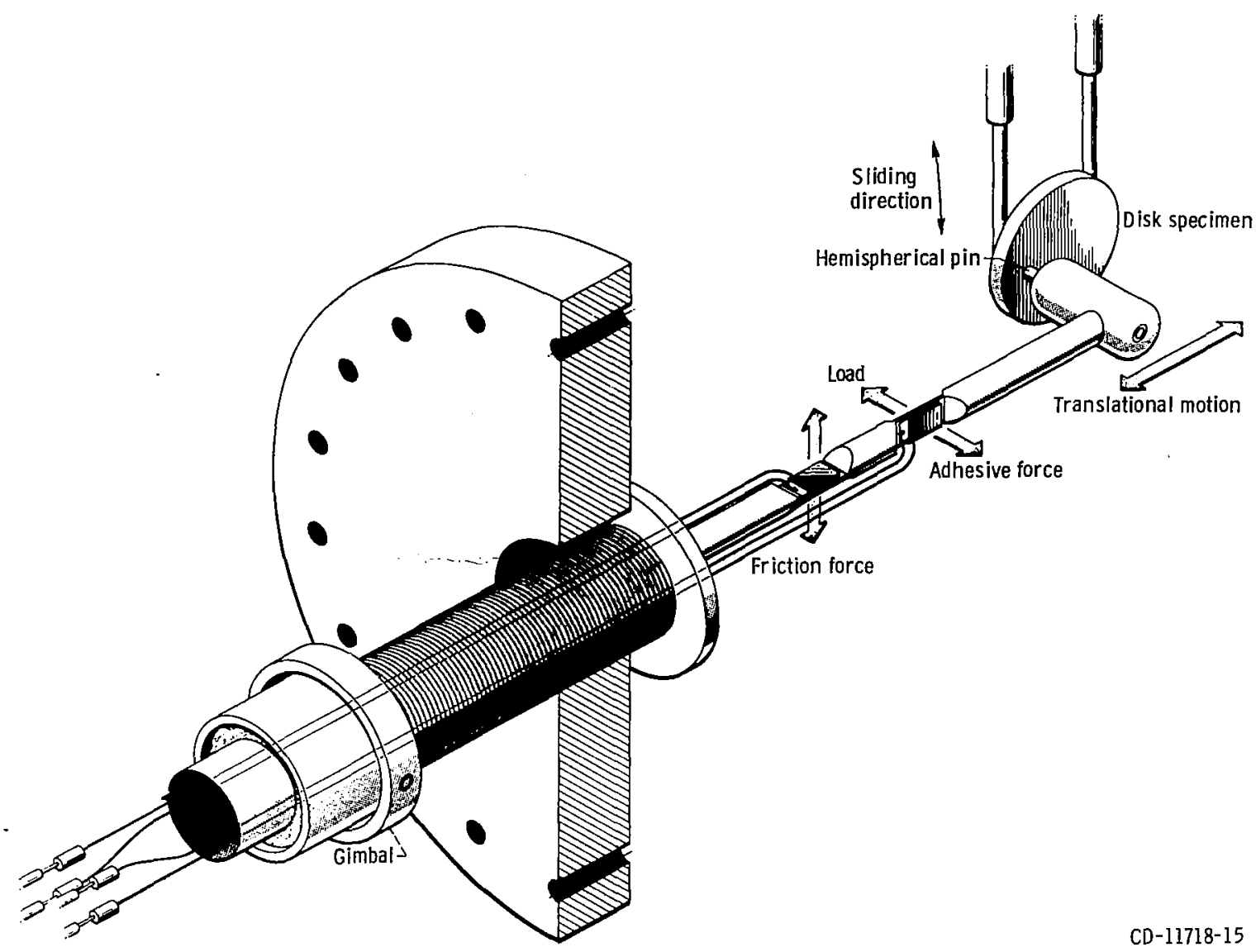

Figure 1. - High-vacuum friction and wear apparatus.

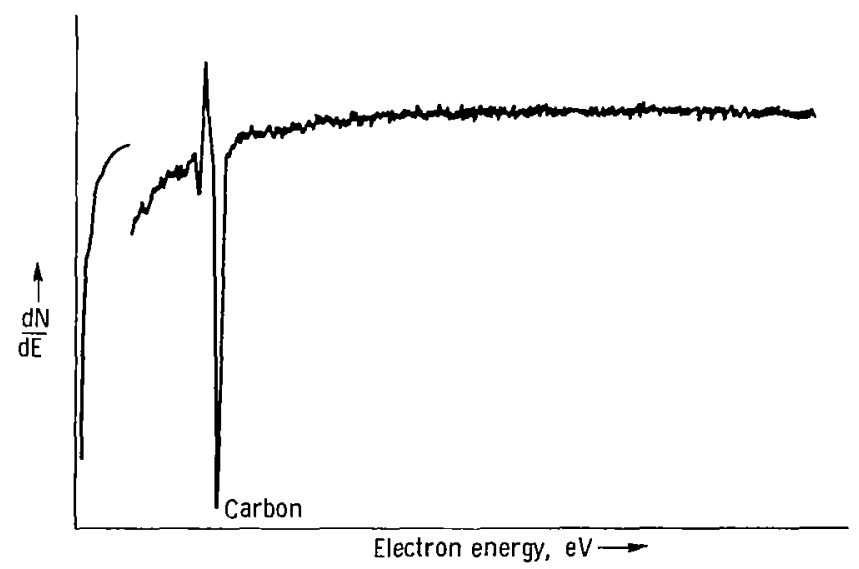

Figure 2. - Auger spectrum for the basal orientation of pyrolytic graphite. 


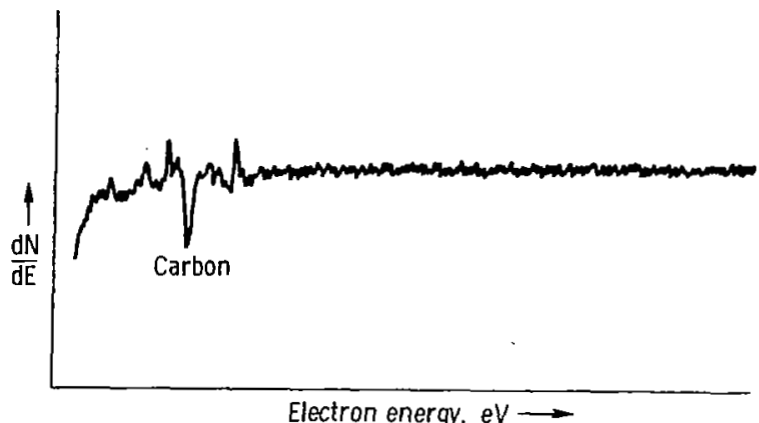

Figure 3. - Auger spectrum for the prismatic orientation of pyrolytic graphite.

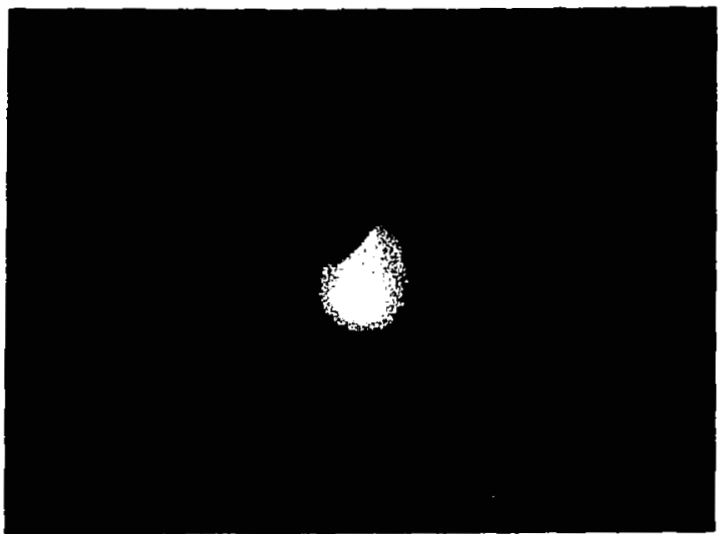

Figure 4. - Low energy electron diffraction pattern (LEED) of basal orientation of pyrolytic graphite.

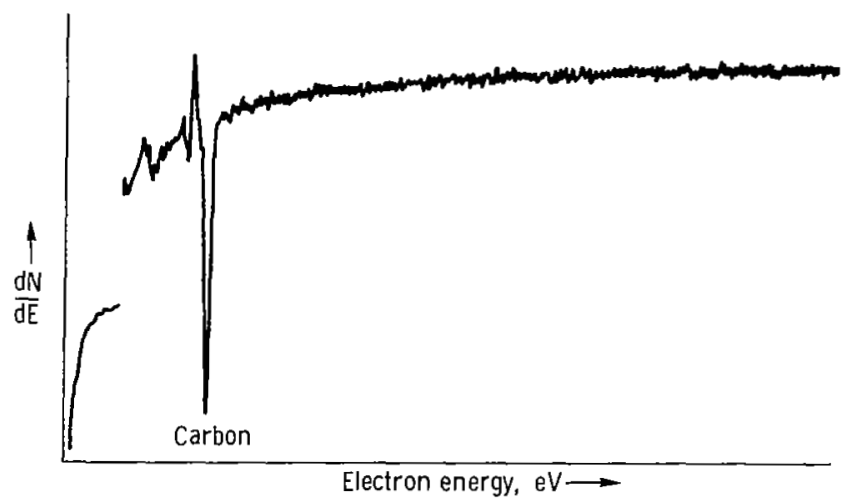

Figure 5. - Auger spectrum for the basal orientation of pyrolytic graphite exposed to 1 atmosphere of hydrogen bromide $(\mathrm{HBr})$. 


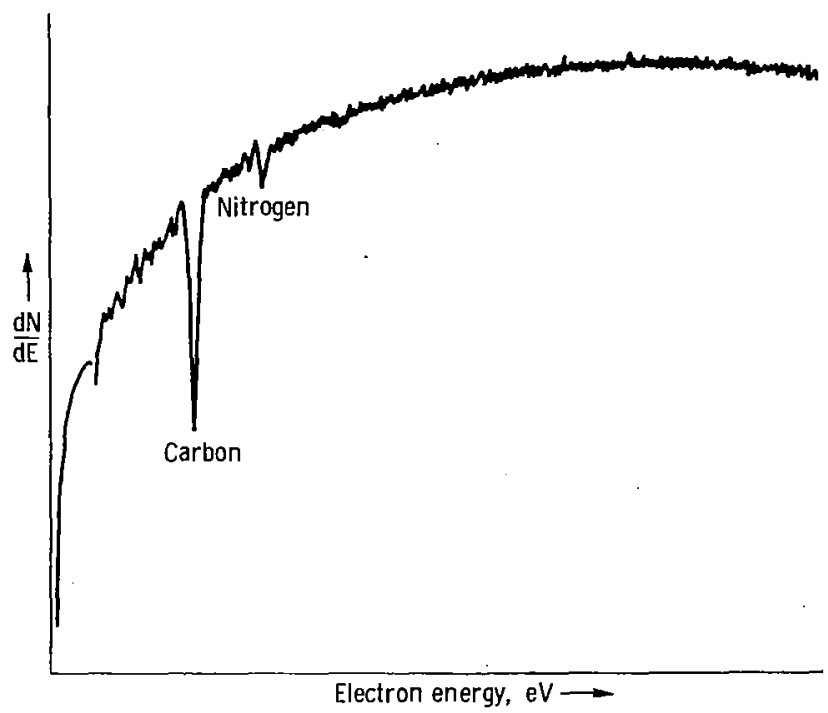

Figure 6. - Auger spectrum for pyrolytic graphite ion bombarded for 1 hour with nitrogen at 10 microns with an applied voltage of 1000 volts.

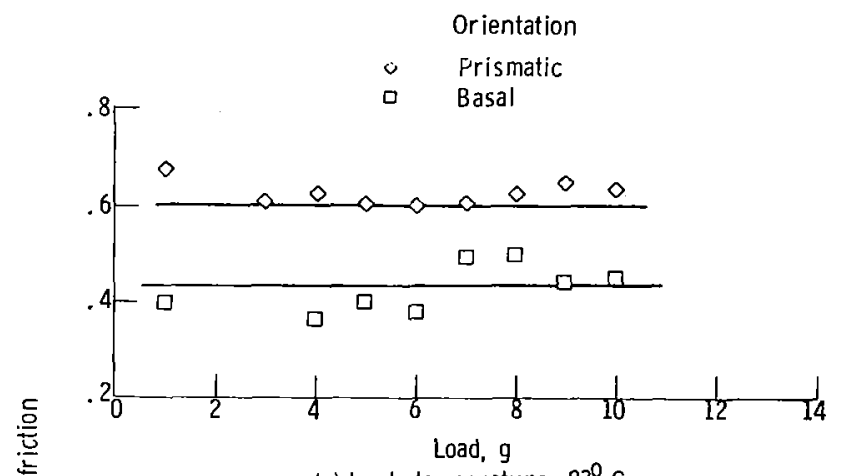

(a) Load; temperature, $23^{\circ} \mathrm{C}$.

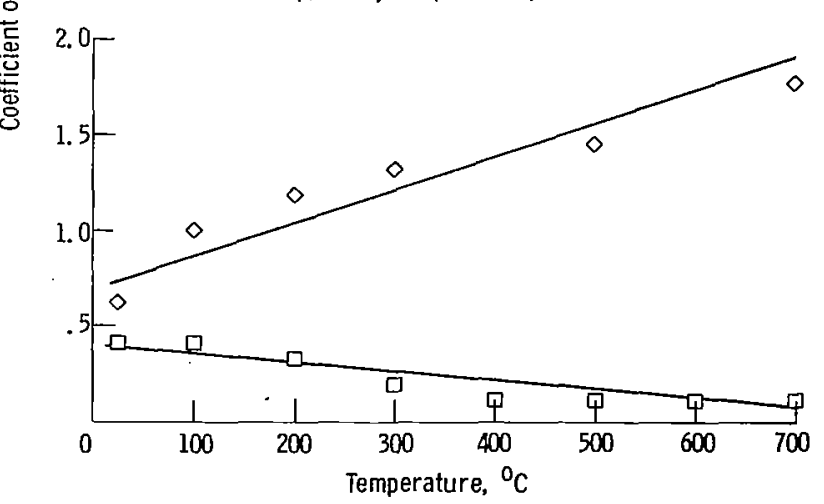

(b) Temperature.

Figure 7. - Coefficient of friction as a function of load and temperature for gold (111) sliding on pyrolytic graphite, Sliding velocity, 0.7 millimeter per minute; pressure, $10^{-10}$ torr. 


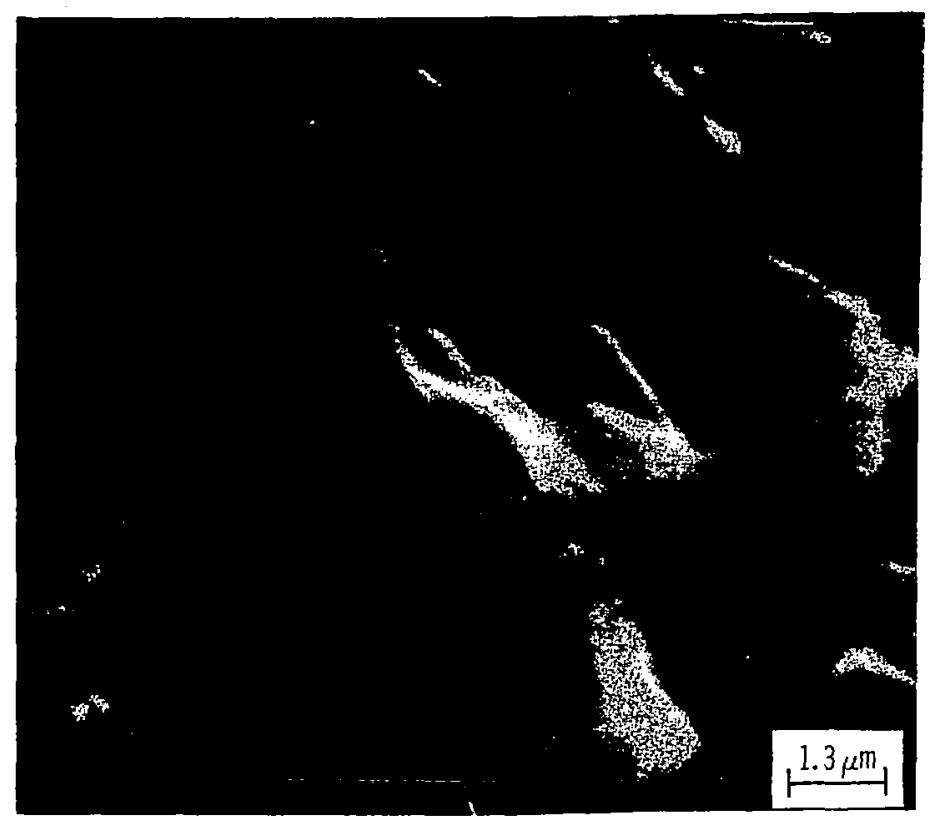

(a) Basai orientation.

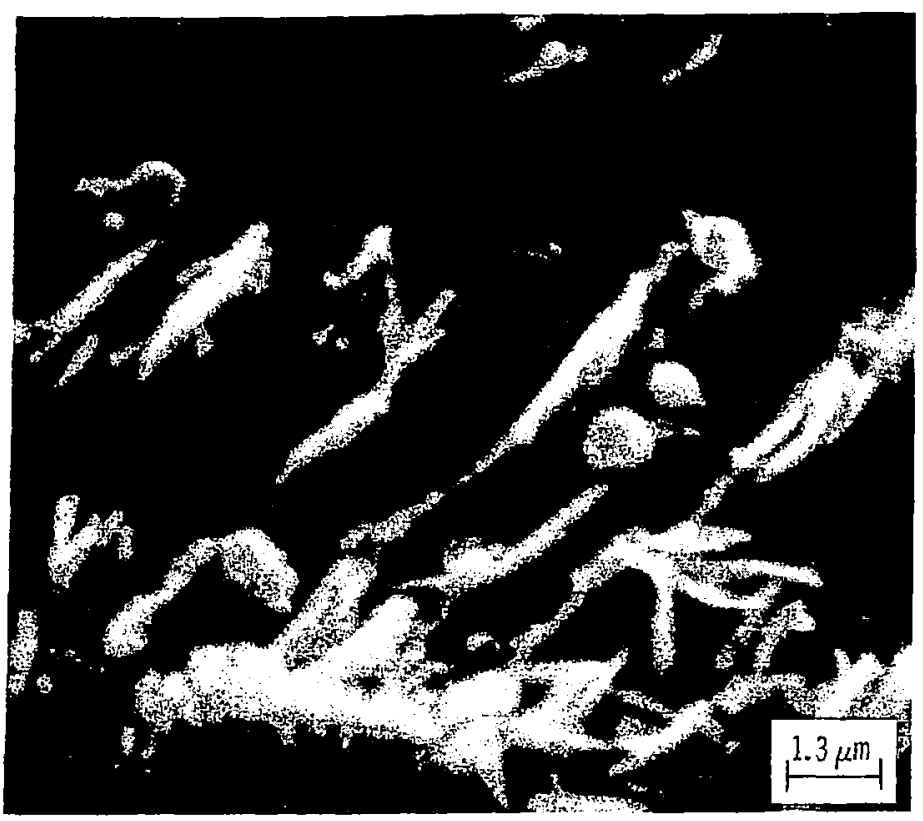

(b) Prismatic orientation.

Figure 8. - Scanning electron micrographs of basal and prismatic orientations of graphite after sliding of a gold pin across the surface of both orientations. Sliding velocity, 0.7 millimeter per minute; load, 10 grams; pressure, $10^{-10}$ torr; temperature, $23^{\circ} \mathrm{C}$. 


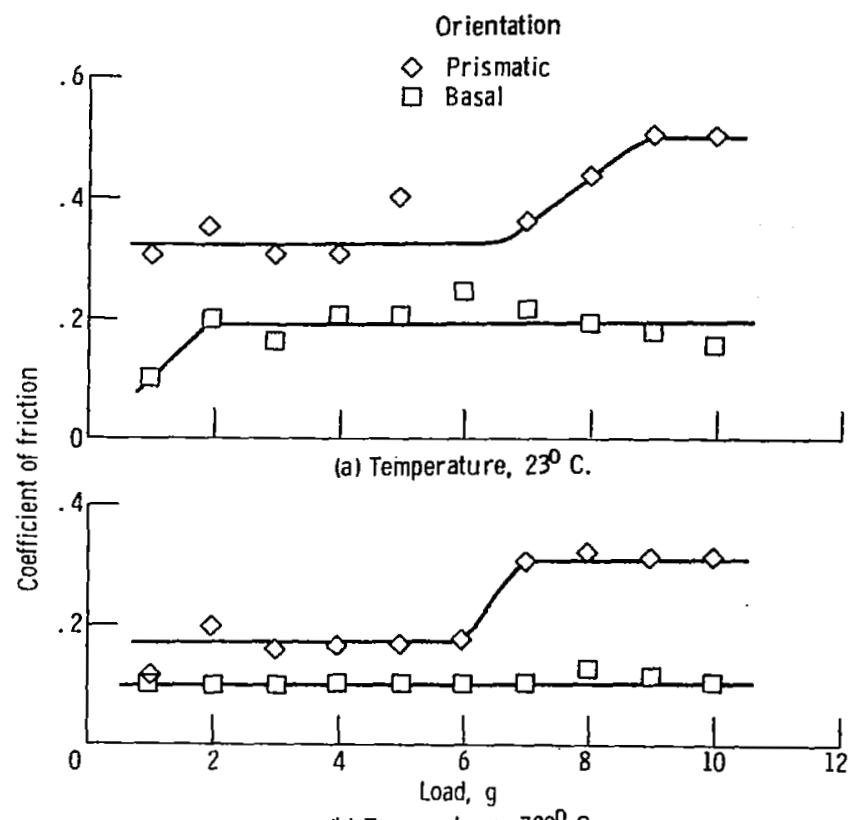

(b) Temperature, $700^{\circ} \mathrm{C}$.

Figure 9. - Coefficient of friction as a function of load for iron (110) single crystal sliding on the basal and prismatic orientation of pyrolytic graphite. Sliding velocity, 0.7 millimeter per minute; pressure, $10^{-10}$ torr.

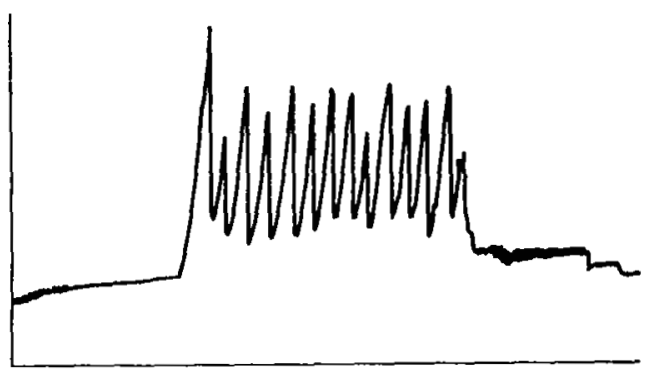

(a) Temperature, $23^{\circ} \mathrm{C}$.

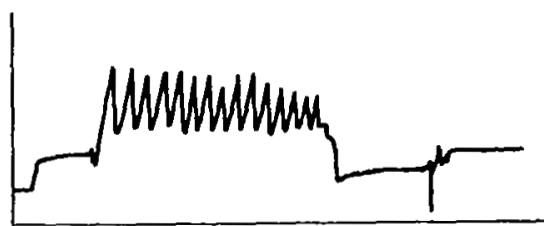

(b) Temperature, $700^{\circ} \mathrm{C}$.

Figure 10. - Friction traces for iron (011) single crystal sliding on the prismatic orientation of pyrolytic graphite. Sliding velocity, 0.7 millimeter per minute; load, 5 grams; pressure. $10^{-10}$ torr. 


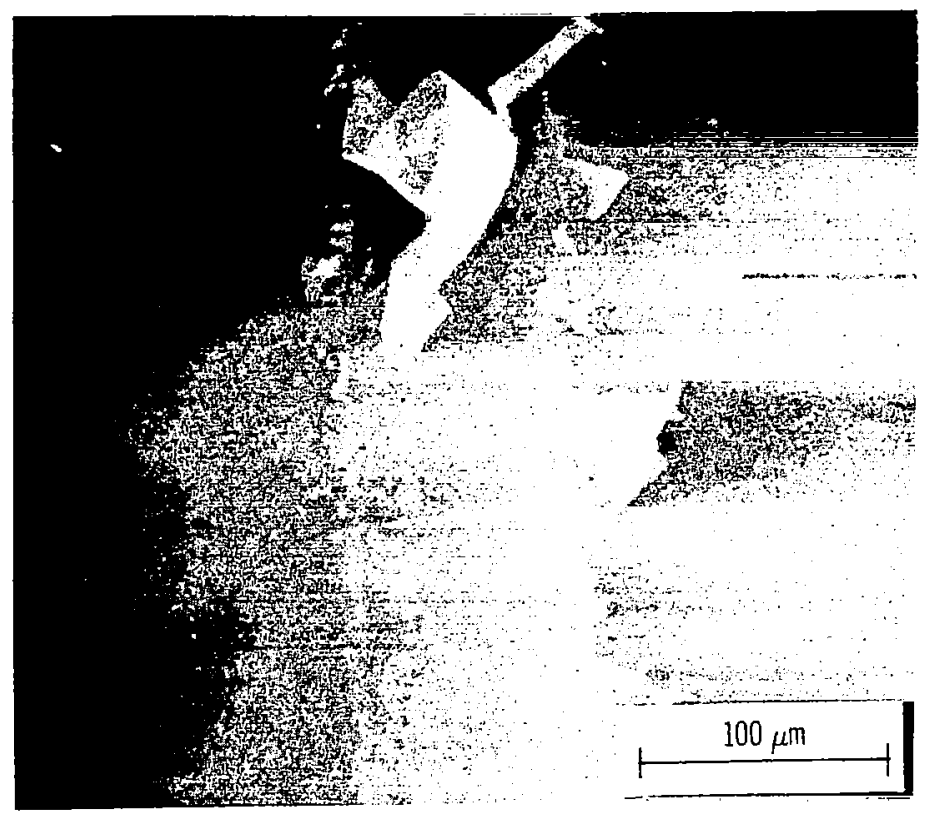

(a) Temperature, $23^{\circ} \mathrm{C}$.

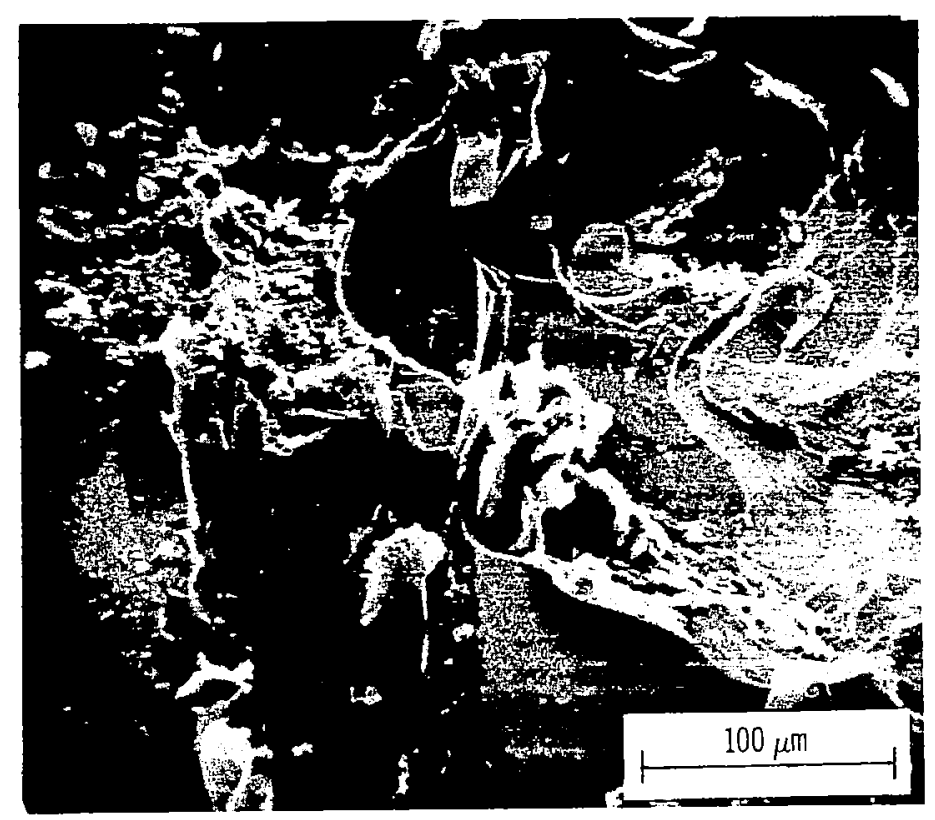

(b) Temperature, $700^{\circ} \mathrm{C}$.

Figure 11. - Scanning electron photomicrographs of the basal orientation of pyrolytic graphite after sliding of an iron pin across the surface at $23^{\circ}$ and $700^{\circ} \mathrm{C}$. Sliding velocity, 0.7 millimeter per minute; load, 10 grams; pressure, $10^{-10}$ torr. 


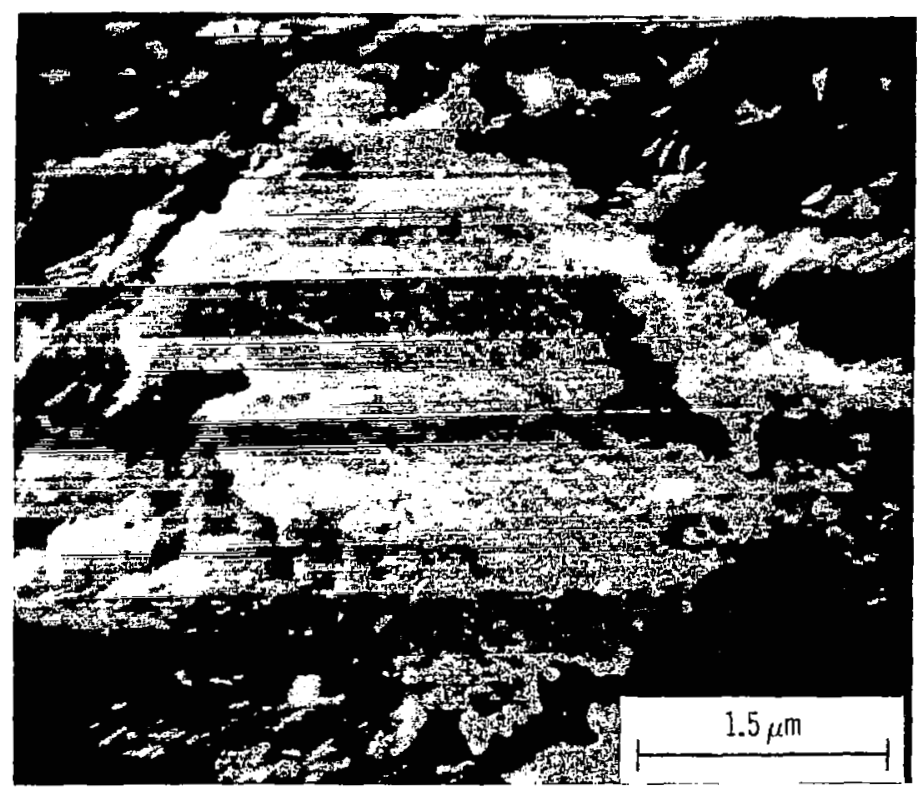

(a) Scanning electron micrograph.

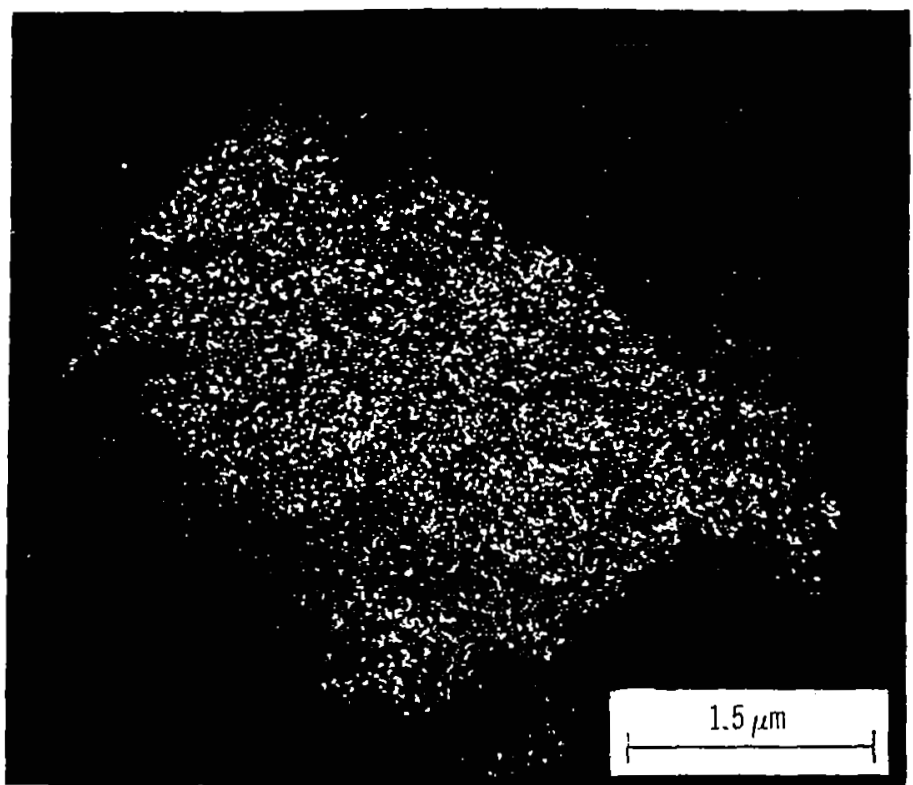

(b) Energy dispersive $X$-ray analysis.

Figure 12. - Scanning electron micrograph and energy dispersive $X$-ray analysis of an iron particle transferred to the prismatic orientation of pyrolytic graphite during sliding. Sliding velocity, 0.7 millimeter per minute; load, 10 grams; pressure, 10-10 torr; temperature, $23^{\circ} \mathrm{C} ; 6000$ cisunts $\mathrm{EDAX}$. 


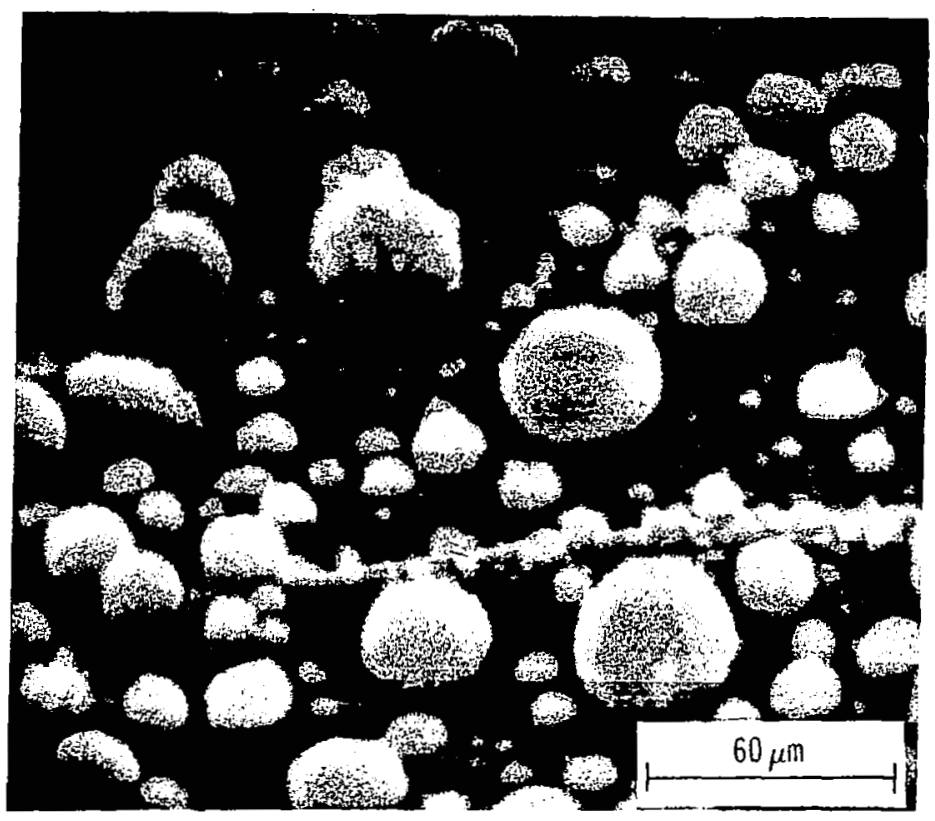

(a) Scanning electron micrograph.

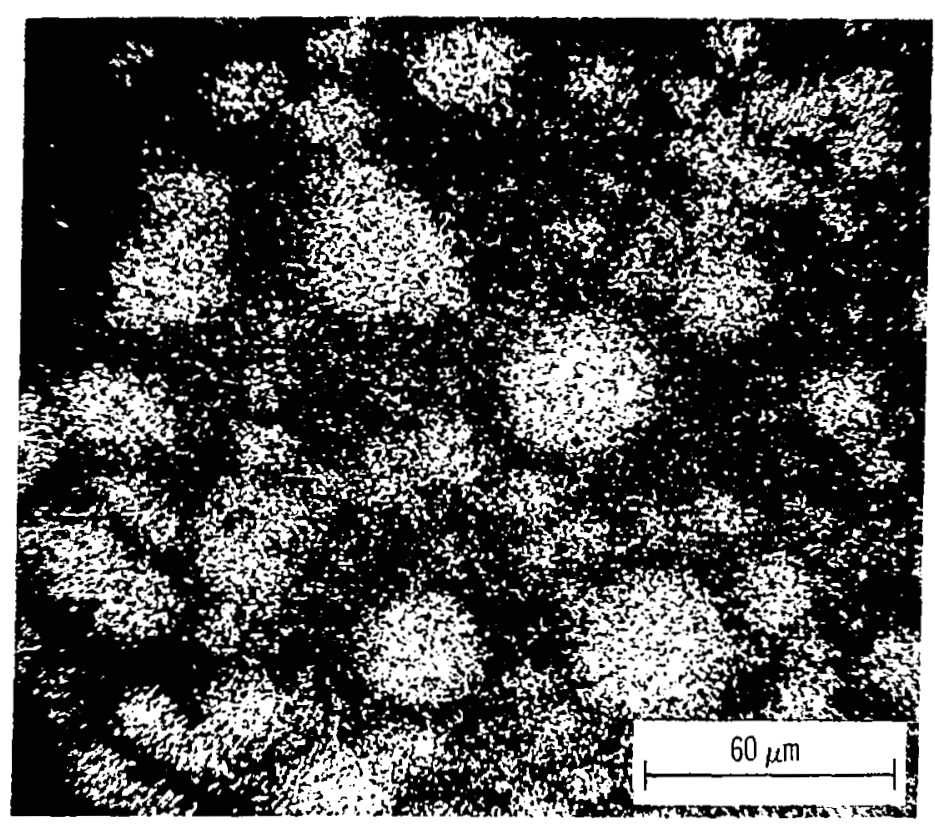

(b) Energy dispersive $X$-ray analysis (FeK $K_{a 1.2) .}$

Figure 13. - Scanning electron micrograph and energy dispersive $X$-ray analysis of iron transferred to the basal orientation of pyrolytic graphite. 


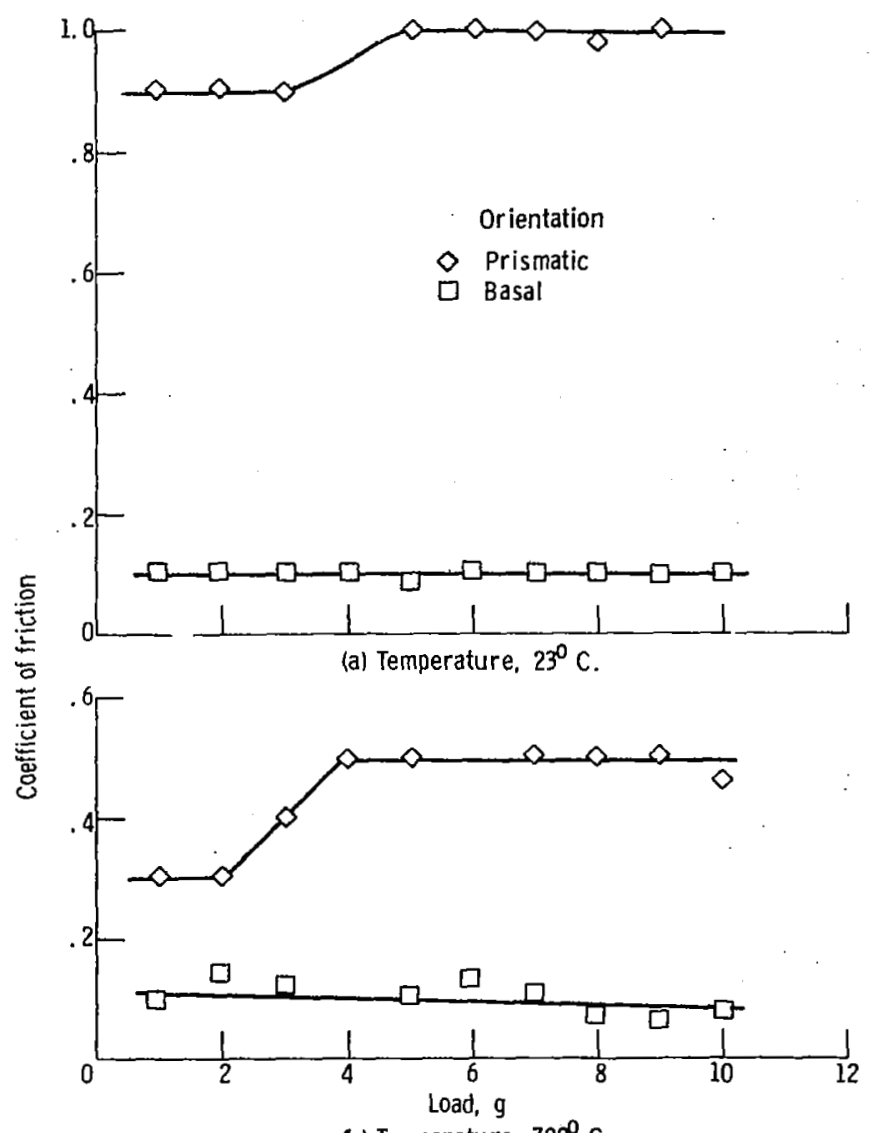

(b) Temperature, $700^{\circ} \mathrm{C}$.

Figure 14. - Coefficient of friction at various loads for tantalum (110) in sliding contact with basal and prismatic orientations of pyrolytic graphite. Sliding velocity, 0.7 millimeter per minute; .pressure, $10^{-10}$ torr. 


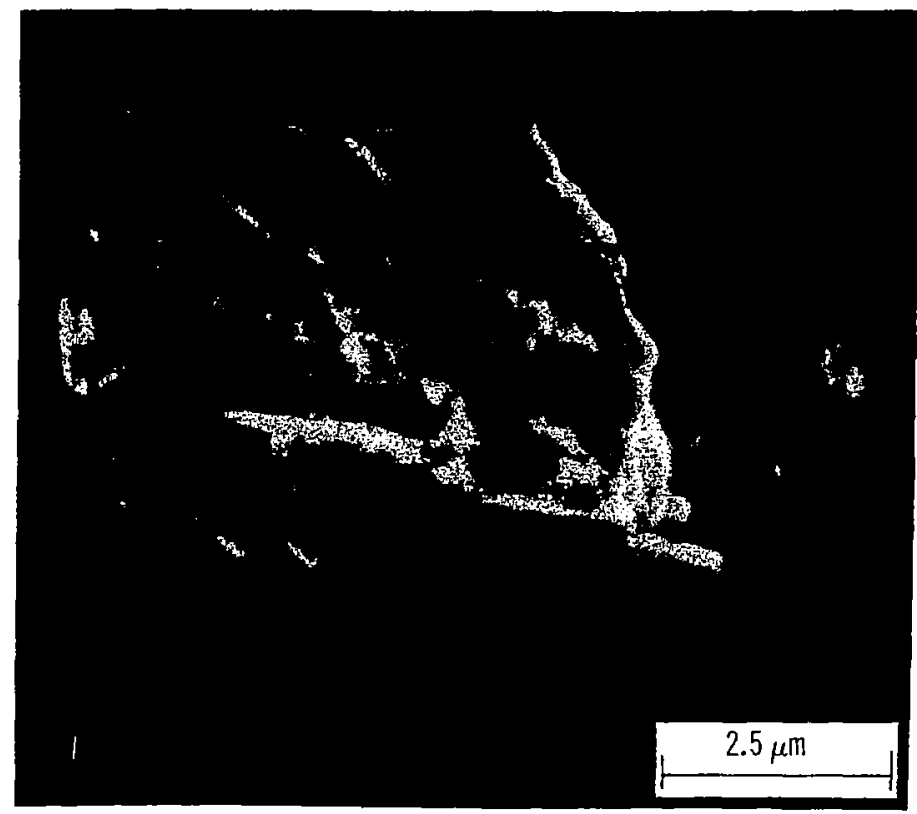

(a) Scanning electron micrograph.

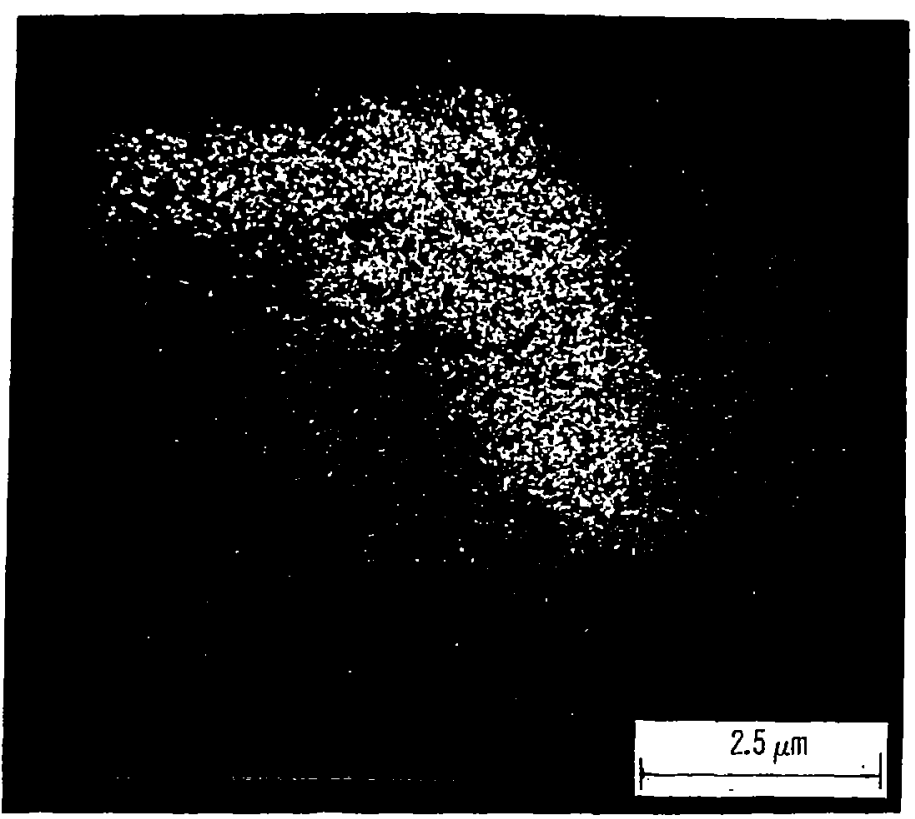

(b) Energy dispersive $\mathrm{X}$-ray analysis.

Figure 15. - Scanning electron micrograph and energy dispersive $X$-ray analysis of tantalum particle transferred from a tantalum pin to the prismatic orientation of pyrolytic graphite. Sliding velocity, 0.7 millimeter per minute; load, 10 grams; pressure, $10^{-10}$ torr; temperature, $23^{\circ} \mathrm{C}$. 


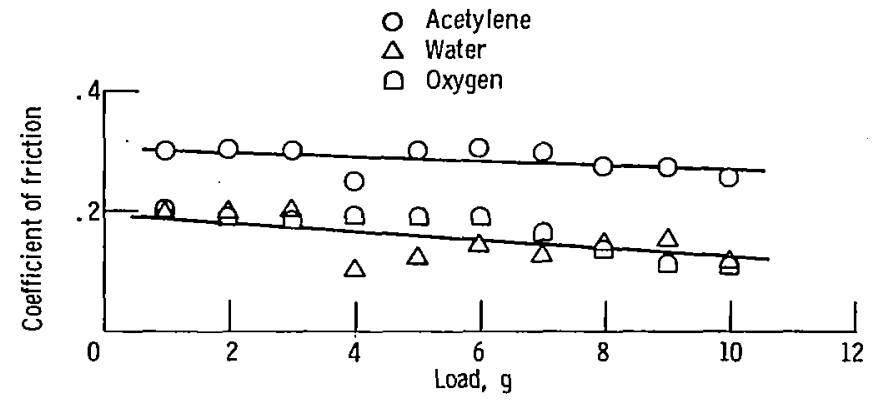

Figure 16. - Coefficient of friction for iron (110) single crystal sliding on the prismatic orientation of pyrolytic graphite. Sliding velocity. 0.7 millimeter per minute; load, I gram; pressure, 760 torr, temperature, $23^{\circ} \mathrm{C}$.

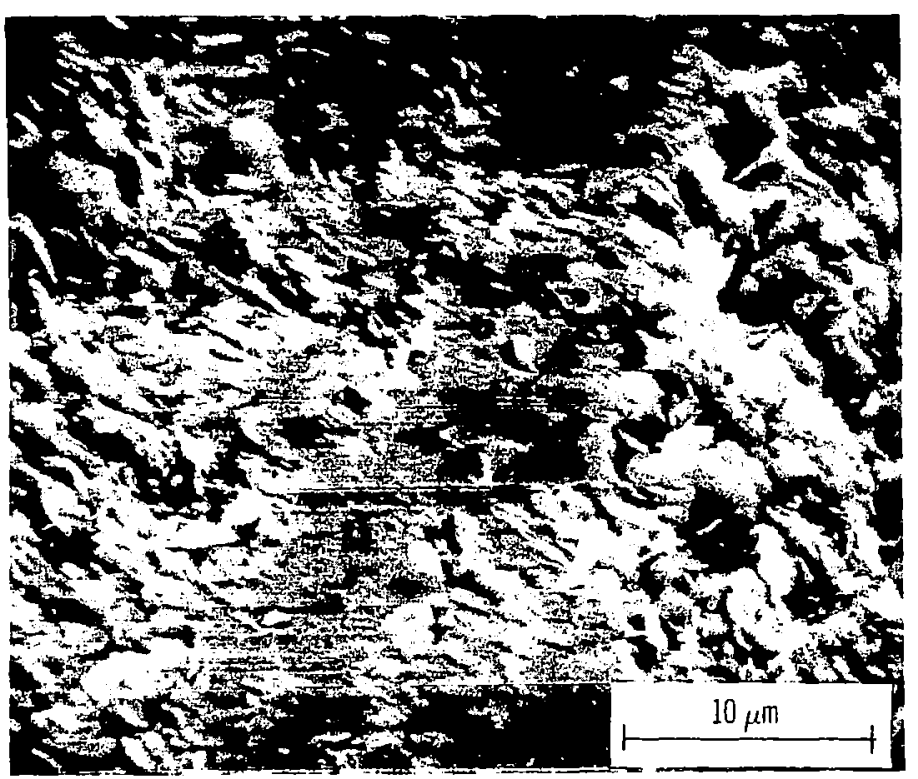

Figure 17. - Scanning electron micrograph of prismatic orientation of pyrolytic graphite after exposure to 1 atmosphere of oxygen and sliding of an iron pin across the surface. Sliding velocity, 0.7 millimeter per minute; load, 10 grams; temperature, $23^{\circ} \mathrm{C}$. (Note reorientation in sliding track of graphite.) 


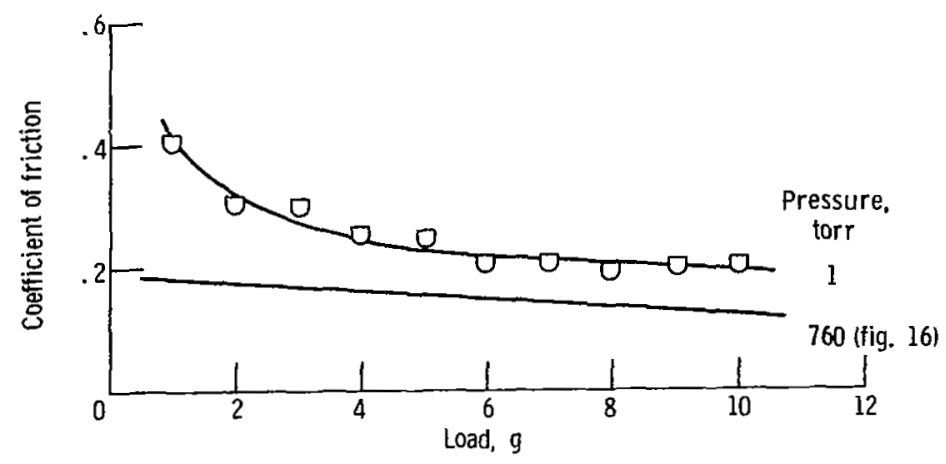

Figure 18. - Coefficient of friction for iron (110) single crystal sliding on the prismatic orientation of pyrolytic graphite in water vapor at two atmospheric pressures. Sliding velocity, 0.7 millimeter per minute; load, I gram; temperature, $23^{\circ} \mathrm{C}$. 